NBER WORKING PAPER SERIES

\title{
MACROECONOMIC EFFECTS OF REGULATION AND DEREGULATION IN GOODS AND LABOR MARKETS
}

\author{
Olivier Blanchard \\ Francesco Giavazzi \\ Working Paper 8120 \\ http://www.nber.org/papers/w8120 \\ NATIONAL BUREAU OF ECONOMIC RESEARCH \\ 1050 Massachusetts Avenue \\ Cambridge, MA 02138 \\ February 2001
}

We thank David Spector for discussions, and Ricardo Caballero, Bill Dickens, Francesco Franco, Paul Joskow, Augustin Landier, Robert Solow, Justin Wolfers, Torsten Persson, and Joseph Zeira for comments. The views expressed herein are those of the authors and not necessarily those of the National Bureau of Economic Research or the National Science Foundation.

(C) 2001 by Olivier Blanchard and Francesco Giavazzi. All rights reserved. Short sections of text, not to exceed two paragraphs, may be quoted without explicit permission provided that full credit, including $($ ) notice, is given to the source. 
Macroeconomic Effects of Regulation and Deregulation in Goods and Labor Markets Olivier Blanchard and Francesco Giavazzi

NBER Working Paper No. 8120

February 2001

JEL No. E24, L16, J50

\begin{abstract}
Product and labor market deregulation are fundamentally about reducing and redistributing rents, leading economic players to adjust in turn to this new distribution. Thus, even if deregulation eventually proves beneficial, it comes with strong distribution and dynamic effects. The transition may imply the decline of incumbent firms. Unemployment may increase for a while. Real wages may decrease before recovering, and so on. To study these issues, we build a model based on two central assumptions: Monopolistic competition in the goods market, which determines the size of rents; and bargaining in the labor market, which determines the distribution of rents between workers and firms. We then think of product market regulation as determining both the entry costs faced by firms, and the degree of competition between firms. We think of labor market regulation as determining the bargaining power of workers. Having characterized the effects of labor and product market deregulation, we then use our results to study two specific issues. First, to shed light on macroeconomic evolutions in Europe over the last twenty years, in particular on the behavior of the labor share. Second, to look at political economy interactions between product and labor market deregulation.
\end{abstract}

Olivier Blanchard

MIT Department of Economics

Bldg. E52-373

Cambridge MA 02139

USA

and NBER
Francesco Giavazzi

Università Bocconi

IGIER

Via Salasco, 3/5

20136 Milano, Italy

and NBER 
Product and labor market regulations are often blamed for the poor European performance of the last 30 years. Remove (many of) these regulations, the argument goes, and Europe will soar. Unemployment will decrease, output will increase. ${ }^{1}$

Deregulation however is fundamentally about reducing and redistributing rents, leading economic players to adjust in turn to this new distribution. Thus, even if deregulation eventually proves beneficial, it is likely to come with both strong distribution and dynamic effects. The transition may imply the disappearance or the decline of incumbent firms. Unemployment may increase for a while. Real wages may decrease before recovering, and so on.

Understanding these dynamic and distribution effects is important, for at least two reasons. As many countries are embarking on a path of deregulation, it may help interpret their macroeconomic evolutions. And it may also help clarify the political economy constraints on deregulation, and thus improve its design. These are the issues we examine in this paper.

We start by developing, in Section 1, a simple general equilibrium model of an economy with both product and labor market regulation. The model is built on two basic assumptions: Monopolistic competition in the goods market, which determines the size of rents; and bargaining in the labor market, which determines the distribution of rents between workers and firms. We think of product market regulation as determining both the entry costs faced by firms, and the degree of competition between firms. We think of labor market regulation as determining the bargaining power of workers.

We then characterize the macroeconomic equilibrium in Section 2. We divide time in two periods, a short run, where the number of firms is given, and a long run, where the number of firms is endogenous, determined by

\footnotetext{
${ }^{1}$ This is for example the theme of a number of studies by the McKinsey Global Institute. See for example McKinsey Global Institute [1997].
} 
an entry condition. For each period, we show how the main macroeconomic variables, in particular the real wage and unemployment, depend on the various dimensions of regulation.

We then turn in Section 3 to the economics of deregulation. (The model is symmetric so the economics of less regulation are the same, with sign reversed, as those of more regulation. Focusing on deregulation is more natural in the current context). This section offers in effect a reinterpretation of the results of Section 2, but with a focus on distribution and dynamic effects of each type of deregulation.

Section 4 discusses two extensions. In our benchmark model, which assumes privately efficient bargaining, the wage is not allocative in the short run. In other words, the wage is typically not equal to the marginal revenue product of labor. Our first extension considers a standard alternative model, known as the right to manage model, in which the wage is equal to the marginal revenue product of labor. The purpose is to show, a contrario, the implications of the efficient bargaining assumption, in particular for the dynamic effects of labor market deregulation. Our benchmark model also assumes linear utility. Our second extension relaxes this assumption and assumes concave utility instead. The reason is that, in that case, the intertemporal trade-offs implied by labor market deregulation are even sharper than in our benchmark model, higher unemployment and lower real wages in the short run, in exchange for lower unemployment and unchanged real wages in the long run.

Having developed the theory, we then turn, in Section 5, to the macroeconomic evidence. We show the light our approach sheds on movements in the labor share and in the "markup", two variables at the center of much recent macroeconomic research (for example Rotemberg and Woodford [1999], Gali and Gertler [1999]). We then focus on the dramatic decline in the labor share in continental Europe since the mid-1980s, in some countries by more than $10 \%$ of GDP. Standard neoclassical mechanisms seem unable to 
account for this evolution, and it was our guess that an explanation might be found in deregulation and the implied changes in the distribution of rents in the economy. Our model indeed offers a tentative interpretation, based on deregulation in the labor market and the implied transfer of rents from workers to firms. If our interpretation is correct, this evolution is good news: The long run effects should be a recovery of the labor share, and a decrease in equilibrium unemployment.

Finally, Section 6 turns to the political economy of deregulation. Based on our analysis, we look at how product market and labor market deregulation affect the welfare of employed and unemployed workers. We look at how governments may combine the two so as to reduce workers' opposition to deregulation. Based on a simple political economy model, we endogenize the various dimensions of regulation, and, within this context, look at the the interactions between product and labor market deregulation. We show how product market deregulation may trigger labor market deregulation. Intuitively, reducing rents in the goods markets reduces the incentives of workers to fight for a share of these rents: The benefits may no longer be worth the costs.

\section{Monopolistic competition, bargaining, and regulation}

We think of an economy in which a number of firms produce differentiated products, using labor. We make two main assumptions. The first is that of monopolistic competition in the goods market, which determines the size of the rents going to firms and their workers. The second is the presence of bargaining in the labor market, which determines how much of the rents go to firms, and how much to their workers.

We divide time in two periods: The "short run", defined as the time over which we can take the number of firms as given. The "long run", defined as the time over which the number of firms is endogenous, determined by an 
entry condition.

We take product market regulation as determining the degree of competition among firms, and the entry cost for firms. We take labor market regulation as determining the degree of bargaining power of workers.

The specific assumptions are as follows:

\section{Workers}

There are $L$ workers/consumers, indexed by $j$. In each period, worker $j$ has a utility function given by:

$$
\left.V_{j}=\left[m^{-1 / \sigma} \sum_{i=1}^{m} C_{i j}(\sigma-1) / \sigma\right)\right]^{\sigma /(\sigma-1)}
$$

where $\sigma=\bar{\sigma} g(m), g^{\prime}()>0,. \bar{\sigma}$ is a constant, and $m$ is the number of products (which is given in the short run, and endogenously determined in the long run).

This specification of utility has two implications:

- Under the assumption that the worker consumes all products in equal proportions (a condition which, in our symmetric model, holds in equilibrium), so $C_{i j}=C_{j} / m$, the utility function implies $V_{j}=C_{j}$. In other words, an increase in the number of products does not increase utility directly. (Technically, this result comes from the presence of $m^{-1 / \sigma}$ in the term in brackets. Absent this term, an increase in the number of products would increase utility for a given level of consumption.)

- The increase in the number of products however increases the elasticity of substitution between products, and by implication the elasticity of demand facing firms. (This result comes from the assumption that $\sigma$, rather than being constant as in the standard Dixit-Stiglitz framework, is increasing in $m$.) 
Thus, to the extent that deregulation leads to a larger number of firms, and by implication a larger number of products (each firm produces a different product), its effect in our model works only through its effect on the monopoly power of firms. This is the effect we think is most important, and we want to capture here.

Each period, worker $i$ can supply either zero or one unit of labor, and spends his income on consumption (there is no saving, or capital in our model, and thus no link across the two periods). His budget constraint for each period, stated in nominal terms, is given by:

$$
\sum_{i=1}^{m} P_{i} C_{i j}=W_{j} N_{j}+\operatorname{Pf}(u)\left(1-N_{j}\right)
$$

where $N_{j}$, labor supply, is equal either to zero (if he does not work) or to one (if he works), $f^{\prime}()<$.0 , and $P$ is the price index associated with consumption:

$$
P \equiv\left(\frac{1}{m} \sum_{i=1}^{m} P_{i}^{1-\sigma}\right)^{1 /(1-\sigma)}
$$

Spending on consumption is equal to labor income if the worker works, and to non-labor income if he does not. The wage equivalent of being unemployed is taken to be a decreasing function of unemployment, $f(u)$. This can be thought of as a shortcut to capture the notion that higher unemployment implies a higher individual probability of remaining unemployed (i.e. a shortcut to a fuller dynamic specification). Or more cleanly, but somewhat hypocritically, it can be interpreted as the marginal product from using an alternative decreasing returns-to-scale common "backyard technology".

Note that under symmetry of consumption (so $C_{i j}=C_{j} / m$ ), and using the budget constraint, the utility of worker $j$ in each period can be rewritten as: 


$$
\left(\frac{W_{j}}{P}-f(u)\right) N_{j}+f(u)
$$

This expression will be useful below.

\section{Products and firms}

Each product is produced by one firm, so $i$ indexes both the product and the firm. The production function of firm $i$ is simply:

$$
Y_{i}=N_{i}
$$

There is no capital. And there is no effect, direct or indirect, of the number of products, and thus of competition, on the productivity of laborwhich is identically equal to one.

Each firm is run by an entrepreneur, with utility also given by (1.1). In each period, the entrepreneur keeps the profit of the firm, and spends it on consumption goods. Nominal profit in firm $i$ is given by $P_{i} Y_{i}-W_{i} N_{i}$, or equivalently:

$$
\left(P_{i}-W_{i}\right) N_{i}
$$

\section{Bargaining}

Each period, each firm bargains with $L / m$ workers. The workers can either work in the firm or be unemployed during the period.

We assume Nash bargaining: Together firm $i$ and the workers choose a wage and a level of employment so as to maximize the (log) geometric average of their surpluses from employment:

$$
\beta \log \left(\left(W_{i}-\operatorname{Pf}(u)\right) N_{i}\right)+(1-\beta) \log \left(\left(P_{i}-W_{i}\right) N_{i}\right)
$$

where the first term reflects the surplus to workers from working in firm 
$i$ (under the assumption of symmetric consumption), the second reflects the profit of firm $i$, and $\beta$ reflects the relative bargaining power of workers.

This assumption is known as (privately) "efficient bargaining". Why assume efficient bargaining? First, it seems like a natural assumption in this context. But also, we want to capture the possibility that firms may not be operating on their demand for labor. In more informal terms, we want to allow for the fact that, when there are rents, stronger workers (a higher $\beta$ ) may be able to obtain a higher wage without suffering a decrease in employment, at least in the short run. Efficient bargaining naturally delivers that implication. But any assumption which relaxed the link between the wage and the marginal revenue product of labor could yield qualitatively similar results. We return to a discussion of alternative assumptions in Section 4 .

\section{The short and the long run}

In the short run, we take the number of firms/products as given. But, in the long run, we assume the number of firms/products to be determined endogenously, by an entry condition. Our purpose in doing so is to capture the effect of the short run distribution of rents between firms and workers on the equilibrium number of firms in the long run.

We assume that firms face a cost of entry equal to $c$, which we think of as coming from product market regulation. We make two assumptions about $c$ :

- We assume that $c$ is a shadow cost. The motivation is our focus on regulation, and the fact that many regulatory barriers to entry take the form of legal and administrative restrictions on entry, rather than direct costs. Except for accounting purposes, this assumption has no implication for the characterization of the equilibrium. It implies that, in our long run equilibrium, existing firms make pure profits; if 
$c$ were an actual cost, these profits would be dissipated in entry costs. In looking at the evolution of the profit share over time, it seems reasonable to think that, in many markets, regulation allows firms to make positive pure profits for a long time, if perhaps not forever.

- The second is that $c$ is proportional to output (or employment, as the two are equal here). The reason for having a proportional rather than a fixed cost is algebraic simplicity: It makes the long run equilibrium easier to characterize. It trivially implies that, in the long run, the profit rate (profit per unit of output) must be equal to $c$, and delivers the result that, in the limit, the equilibrium converges to the competitive equilibrium as $c$ goes to zero. It obviously eliminates the standard issues examined by models of monopolistic competition, such as optimality of the number of products and so on. But they are not the focus here, and either allowing for a non-regulatory fixed cost or allowing the regulatory cost itself to be a fixed cost would not make any substantial difference to the results we want to focus on here.

\section{Regulation}

We think of regulation as being captured, admittedly in abstract fashion, by three parameters in the model:

- We think of $\bar{\sigma}$ and $c$ as reflecting two dimensions of product market regulation. In the context of European integration for example, decreases in $\bar{\sigma}$ may reflect the elimination of tariff barriers, or standardization measures making it easier to sell domestic products in other European Union countries. Decreases in $c$ may come, for example, from the elimination of state monopolies, or the reduction of red tape associated with the creation of new firms. 
- We think of $\beta$ as reflecting any aspect of labor market regulation which increases the bargaining power of workers, ranging, for example, from the existence and the nature of extension agreements, to closed shop arrangements, to the rules on the right to strike.

Our goal is to show how these three parameters determine the size and the distribution of rents, and by implication, the macroeconomic equilibrium.

\section{Short and long-run equilibrium}

The easiest way to characterize the equilibrium is to do so in three steps, starting with the short run partial equilibrium, then turning to the short run general equilibrium, and finally to the long run general equilibrium.

\section{The short run partial equilibrium}

Consider the problem faced by firm $i$, producing good $i$. Given the preferences of workers and entrepreneurs, the demand for good $i$ (by workers and entrepreneurs) is given by:

$$
Y_{i}=\frac{Y}{m}\left(\frac{P_{i}}{P}\right)^{-\sigma}
$$

where $Y$ is total demand (total output), and $Y_{i}$ the demand for good $i$. At a relative price of one, the firm faces a demand equal to one- $m$ th of total demand. The elasticity of demand with respect to the relative price is equal to $(-\sigma)$.

Taking $Y, P$, and the unemployment rate $u$ as given, firm $i$ and the workers associated with firm $i$ choose employment $N_{i}$, the price $P_{i}$, and the wage $W_{i}$ so as to maximize:

$$
\beta \log \left(\left(W_{i}-P f(u)\right) N_{i}\right)+(1-\beta) \log \left(\left(P_{i}-W_{i}\right) N_{i}\right)
$$


where, from the production function, $N_{i}=Y_{i}$, and demand $Y_{i}$ is given by $(2.1) .^{2}$ It follows that:

- The relative price $P_{i}$ chosen by the firm (and the workers) is given by:

$$
\frac{P_{i}}{P}=(1+\mu(m)) f(u)
$$

where $\mu(m)$, the markup of the relative price over the reservation wage, is given by:

$$
\mu(m)=\frac{1}{\bar{\sigma} g(m)-1} \text { so } \mu^{\prime}(m)<0
$$

- The real consumption wage (the wage in terms of the consumption basket), $W_{i} / P$, is given by:

$$
\frac{W_{i}}{P}=(1-\beta) f(u)+\beta \frac{P_{i}}{P}
$$

So, using equation (2.2):

$$
\frac{W_{i}}{P}=[1+\beta \mu(m)] f(u)
$$

A graphical representation of the partial equilibrium is given in Figure 1. Employment (equivalently, output) is measured on the horizontal axis, the relative price, $P_{i} / P$, and the real consumption wage, $W_{i} / P$, on the vertical axis.

\footnotetext{
${ }^{2}$ Note the implicit assumption that, when choosing the price $P_{i}$, both workers and the firm $i$ ignore the effect on the change in $P_{i}$ on the price of a consumption basket, $P$. This-standard-approximation is clearly better the larger the number of goods.
} 


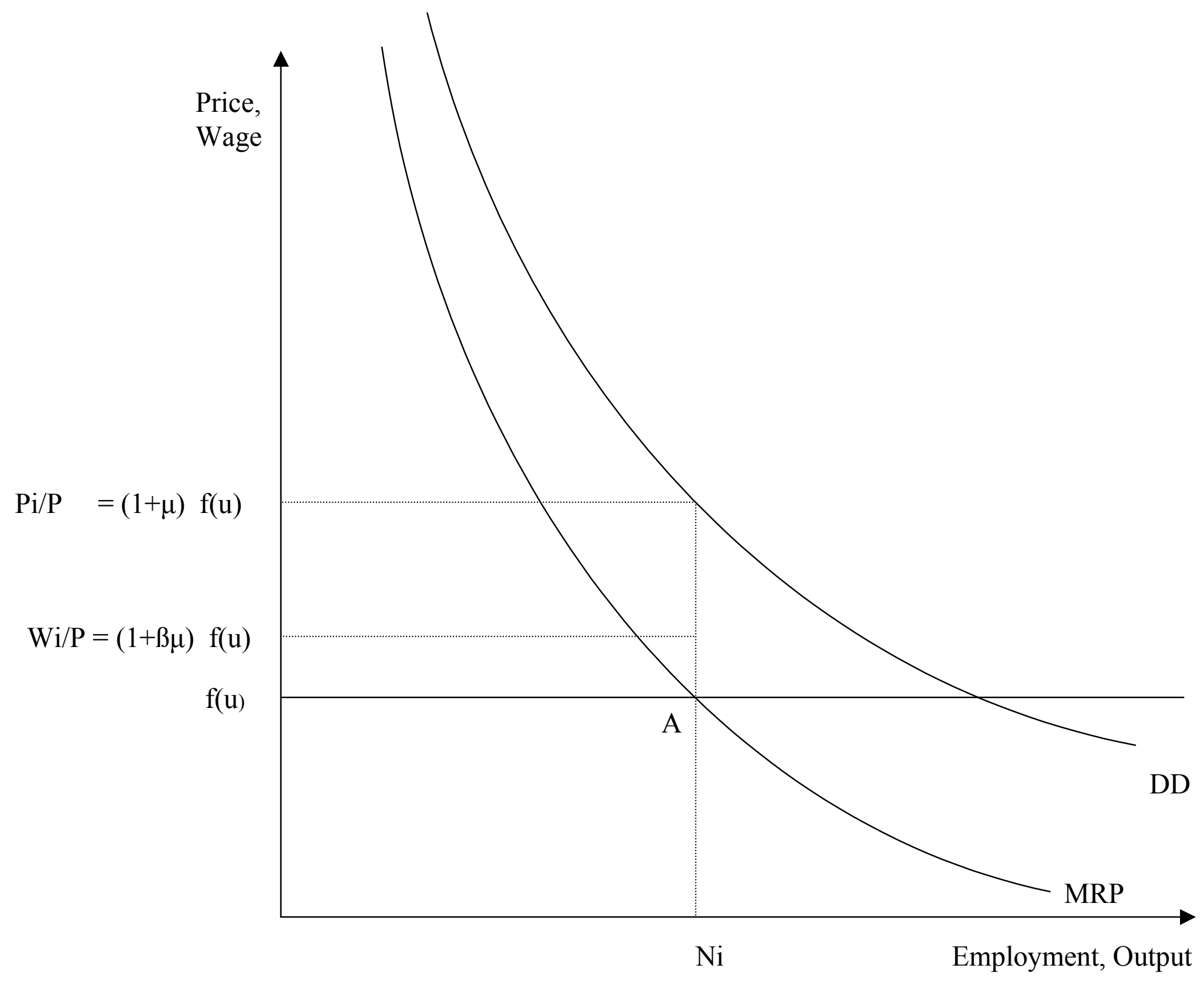

Figure 1. Partial equilibrium 
The demand curve and marginal revenue product curves are drawn as DD and MRP. The reservation wage is drawn as the horizontal line, at $f(u)$.

From the point of view of workers and the firm, the efficient level of employment is such that the marginal revenue product of labor is equal to the reservation wage, so at point $A$, with associated level of employment $N_{i}$. This in turn implies the choice of a relative price, $P_{i} / P$, on the demand curve, so a price equal to one plus a markup $\mu$, times the reservation wage. In usual fashion, the markup is related to the elasticity of demand by $\mu=1 /(\sigma-1)$.

Given the relative price, rents per unit of output are given by $\left(P_{i} / P-\right.$ $f(u)$ ), or $\mu f(u)$. The workers get a proportion $\beta$ of those rents, so the real wage, which plays no allocative role under efficient bargaining, is equal to $(1+\beta \mu f(u))$.

Note that, in partial equilibrium, the real wage is an increasing function of both $\beta$ and $\mu$ :

- The higher $\beta$, the higher the proportion of rents going to workers. And because the reservation wage is unaffected, the increase in the wage has no effect on employment.

- The higher $\mu$, thus the higher the real wage. The firm receives larger rents, of which some proportion goes to the workers.

\section{General equilibrium. Short run.}

In partial equilibrium, each firm chooses its relative price $P_{i} / P$ freely. But, in general equilibrium, not all firms can have a relative price greater than one. Indeed, under our symmetric assumptions, all prices must be equal in general equilibrium. Putting $P_{i} / P=1$ in equation (2.2) implies:

$$
1=(1+\mu(m)) f(u)
$$


In the short run, the number of firms is given, so $\sigma=\bar{\sigma} g(m)$ is given, and by implication so is $\mu(m)$. Given $\mu(m)$, equation (2.4) determines the equilibrium unemployment rate.

Replacing $f(u)$ by $1 /(1+\mu(m))$ in equation (2.3), the real wage is given in turn by:

$$
\frac{W_{i}}{P}=\frac{(1+\mu(m) \beta)}{(1+\mu(m))}
$$

The equilibrium is characterized in Figure 2. Figure 2 starts by replicating Figure 1. Equilibrium is still at the point where the marginal revenue product of labor is equal to the reservation wage, at point $A$. But now, the implied relative price must be equal to 1 . Given that the relative price is a markup over the reservation wage, and given that the markup is fixed in the short run, this condition determines the reservation wage, and in turn the equilibrium level of unemployment. The real wage is still set as a weighted average of the reservation wage and the relative price.

Return to the effects of $\beta$ and $\mu$ on the real wage, now in the short run general equilibrium:

- As was the case in partial equilibrium, the real wage is still an increasing function of $\beta$.

An increase in $\beta$ increases the proportion of rents going to workers, and thus leads to a higher real wage. And, because, in the short run, the real wage is not allocative, this higher real wage has no effect on employment, or unemployment.

- In contrast however to the partial equilibrium case, the real wage is now a decreasing function of $\mu$.

This is because there are now two effects at work. The first is the partial equilibrium effect we saw earlier: A higher $\mu$ means higher 


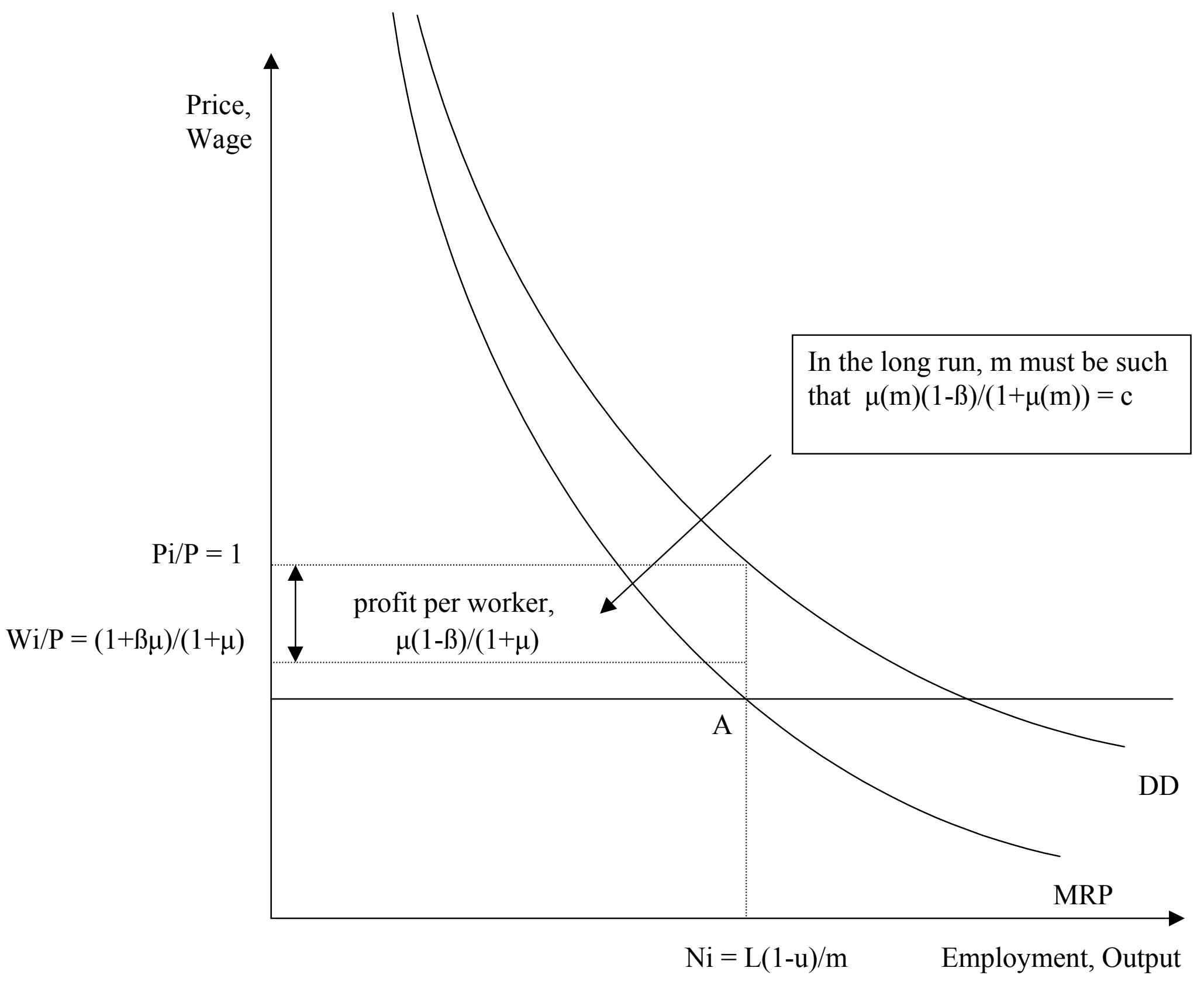

Figure 2. General equilibrium 
rents to the firm where the worker works, leading to a higher real wage. The second is the general equilibrium effect. The rents going to firms come from consumers, who now pay more for the goods they buy. So workers gain as workers, but lose as consumers. Because, as workers, they only get a proportion $\beta$ of the rents, the second effect dominates the first. The real wage goes down.

\section{General equilibrium. Long run}

In the short run, the real wage is not allocative, and the size of the rents left to firms has no effect on their employment decision. In the long run however, rents determine entry or exit of firms. In the long run, rents must cover entry costs. ${ }^{3}$ Given our assumption that entry costs are proportional to output, this condition takes the simple form:

$$
\frac{\mu(m)(1-\beta)}{(1+\mu(m))}=c
$$

Profit per worker must be equal to the shadow cost $c$. This equation determines the equilibrium number of products $m$. Recall that the number of products determines the elasticity of substitution between products, and thus the elasticity of demand facing firms. Thus, the number of products must be such as to generate a degree of competition consistent with profits equal to entry costs.

Using the definition of $\mu(m)$, equation (2.6) can be rewritten as:

$$
\bar{\sigma} g(m)=\frac{(1-\beta)}{c}
$$

\footnotetext{
${ }^{3}$ Our two-period model cannot capture the specific dynamics of entry and exit. Presumably, if rents are less than entry costs, firms which die will not be replaced until rents have recovered sufficiently to justify entry. If rents are larger than entry costs, firms will enter until rents have been bid down to entry costs.
} 
Given that $g^{\prime}()>$.0 , the equilibrium number of products is a a decreasing function of $\bar{\sigma}$ : More competition for a given number of firms decreases rents, making entry less attractive. The number of firms is also a decreasing function of $\beta$ : A smaller proportion of rents going to firms also makes entry less attractive. And the number of firms is a decreasing function of $c$ : Higher entry costs require higher rents, leading to a smaller number of firms.

Replacing the markup from (2.6) in (2.4), the unemployment rate is given by:

$$
f(u)=1-\frac{c}{(1-\beta)}
$$

The higher $c$ or the higher $\beta$, the higher the markup required to cover entry costs, thus the smaller the equilibrium reservation wage, and, in turn, the higher the unemployment rate.

Finally, replacing the markup from (2.6) in (2.5), the real wage is given by:

$$
\frac{W_{i}}{P}=1-c
$$

The intuition is straightforward: Productivity is equal to one. Firms must receive $c$ per unit in order to cover entry costs. The real wage must therefore be equal to $1-c$.

Return once again to the role of $\beta$ and $\mu$ on the real wage:

- Because the supply of firms is fully elastic in the long run, an increase in $\beta$ no longer increases the real wage. The effect now shows up in higher unemployment. Higher $\beta$ means lower rents for firms, and for given entry costs, a lower number of firms, a higher markup, a lower reservation wage, and so a higher rate of unemployment.

- The markup, $\mu$, is no longer an exogenous parameter, but is now determined in equilibrium by both $\beta$ and $c$, so we must look at the 
effects of $c$ instead. An increase in $c$, which increases the equilibrium value of $\mu$, leads to a decrease in the real wage. But, now, it leads also to an increase in the unemployment rate. A higher $c$ leads to a smaller number of firms, a higher markup, a lower required reservation wage, and a lower unemployment rate.

Having characterized the equilibrium, we can now turn to the effects of various dimensions of deregulation. While the results have already been implicitly given, something is gained from the discussion. We do so in the next section.

\section{Deregulation}

Let us start with the two dimensions of product market deregulation, then turn to labor market deregulation.

\section{Product market deregulation. An increase in $\bar{\sigma}$}

Suppose the government increases $\bar{\sigma}$, increasing competition in the product market, for a given number of firms.

In the short run, firms facing more elastic demand decrease their markup, leading in turn to both an increase in real wages, and a decrease in unemployment.

The favorable effects however vanish in the long run. The reason is, given an unchanged entry cost, the decrease in the profit rate leads a decrease in the number of firms over time (Because it is not profitable to enter, firms which die are not replaced). In the long run, the profit rate must go back to its initial, pre-deregulation, level. But for the profit rate to return back to its initial level, so must the markup. By implication, so do the unemployment rate and the real wage.

In short, this dimension of product market deregulation is eventually 
self-defeating: The favorable short-run effects disappear over time and the economy returns to its pre-deregulation equilibrium.

These results are probably too strong, in that we take $c$, the entry cost, as given, when looking at changes in $\bar{\sigma}$. In practice, many deregulation measures are likely to affect $c$ as well. If for example, we think of $c$ as the shadow cost of a quantitative restriction on the number of firms (for example, the granting of a market to a monopoly firm), then these firms will stay in the market even if $\bar{\sigma}$ increases. More formally, the shadow cost $c$ will go down one-for-one with the profit rate, leading to the same favorable effects of deregulation in the short-run and the long-run. Netherveless, the results make an important point: To the extent that rents in the economy ultimately come from entry costs, then, if nothing is done to decrease entry costs, attempts to increase competition by other means are likely to be partly self-defeating.

\section{Product market deregulation. A decrease in $c$}

The previous argument suggests that the second dimension of product market deregulation, a decrease in entry costs, is more likely to be favorable, even in the long run. And indeed, it is.

Obviously, from our assumption that the number of firms is fixed in the short run, the decrease in entry costs has no effect in the short run. But in the long run, it leads to entry of firms, thus to a higher elasticity of demand, a lower markup, and thus lower unemployment and a higher real wage. (What happens to the size of incumbent firms, an aspect which will be relevant when we turn to the political economy of deregulation, is theoretically ambiguous: The number of firms increases, but, as the unemployment rate decreases, total employment increases as well. To the extent that, as seems plausible, the relative increase in total employment is smaller than the relative increase in the number of firms, employment in incumbent firms decreases.) 
In short, this dimension of product market deregulation works because it attacks the problem at the root, decreasing the rents the firms require to enter and stay in the market. This allows for more competition, and in turn lower unemployment and higher real wages.

Note that, for neither dimension of product market deregulation, is there an intertemporal trade-off for real wages or unemployment. The first dimension leads to higher real wages and lower unemployment in the short-run and no long-run effect, the second to no short-run effect, and higher real wages and lower unemployment in the long run. Things are quite different in the case of labor market deregulation, to which we now turn.

\section{Labor market deregulation. A decrease in $\beta$}

Consider a decrease in $\beta$, a decrease in the bargaining power of workers.

In the short run, workers give up rents; From (2.5), their real wage decreases; equivalently, the profit rate increases. But this change in the factor income distribution has no effect on unemployment, which remains given by (2.4). Thus, workers clearly lose in the short run.

In the long run however, the larger rents left to firms lead to entry, until profit rates have returned to their initial level, until the profit rate is again equal to $c$. As firms enter, competition increases, the markup decreases, leading to a decrease in the unemployment rate, and an increase in the real wage. Indeed, in the long run, the unemployment rate is lower than prederegulation. The real wage is back to its initial, pre-deregulation, level: The short run decrease in real wage due to the decrease in $\beta$ is exactly offset by the decrease in the markup.

In short, labor market deregulation works by changing the distribution of rents in favor of firms, leading to more competition in the long run, and lower unemployment. In contrast to product market deregulation, it comes with a sharp intertemporal trade-off, lower real wages in the short run in 
exchange for lower unemployment in the long run. This will be relevant when we discuss the political economy of labor market deregulation in Section 6 .

We have shown how different dimensions of deregulation have different distribution and dynamic effects on the economy. We now want to use these results in two ways, first to look at recent macroeconomic evolutions in Europe, then to think about the political economy of labor and product market deregulation. Before doing so, we discuss two extensions of the basic model.

\section{Extensions}

Our model is based on a number of strong simplifying assumptions, from linear utility, to the form of bargaining. Given our focus on the effects of labor market deregulation later on, we explore two extensions. In the first, we modify the nature of bargaining in the labor market, with the implication that the wage is now allocative, even in the short run. The main purpose is to show, a contrario, the implications of efficient bargaining for the effects of labor market deregulation. In the second, we consider the implications of concave utility. In this case, the intertemporal trade-off faced by workers in the event of labor market deregulation is even starker than in our benchmark model: lower real wages and higher unemployment in the short run, in exchange for lower unemployment in the long run.

\section{Ex-post determination of employment}

Under our assumption that bargaining is privately efficient, the wage plays only a distributive role in the short run. Under that assumption, labor market deregulation, in the form of a decrease in $\beta$, gives rise to a sharp intertemporal trade-off, lower wages in the short run, in exchange for lower unemployment only in the long run. 
Under the alternative assumption that employment is chosen ex-post by firms so as to maximize profit given the bargained wage - the so called "right to manage" assumption, things look quite different. There is no intertemporal trade-off from labor market deregulation: A decrease in $\beta$ leads to lower unemployment and unchanged real wages, both in the short run and in the long run. The reason is that the real wage is now allocative even in the short run, and a decrease in $\beta$ now functions as an exogenous decrease in the reservation wage in the benchmark model.

Consider the partial equilibrium first. ${ }^{4}$ If firms can choose employment ex-post, then workers and the firm maximize (1.2) by choosing a wage equal to:

$$
\frac{W_{i}}{P}=(1+\beta \mu) f(u)
$$

In partial equilibrium, and for a given unemployment rate, the wage turns out to be the same as under efficient bargaining. But the relative price is different, and given by:

$$
\frac{P_{i}}{P}=(1+\mu) \frac{W_{i}}{P}=(1+\mu)[1+\beta \mu] f(u)
$$

The price is now a markup over the real wage, not the reservation wage. Because firms take the bargained wage as given when choosing employment, the wage is now allocative. Equation (4.2) shows the "double marginalization" present in the economy. The wage is equal to $(1+\beta \mu)$ times the reservation wage, and the price is equal to $(1+\mu)$ times the real wage.

Turn to the short-run general equilibrium. The unemployment rate must be such that the relative price in (4.2) is equal to one, so:

$$
1=(1+\mu)[1+\beta \mu] f(u)
$$

\footnotetext{
${ }^{4}$ What follows is well travelled ground. See in particular Layard and Nickell [1990].
} 
This expression differs from that in the benchmark model because of the presence of the term in brackets. This term is greater than one, so, for a given value of $\mu$, equilibrium unemployment is higher than under efficient bargaining.

Because the price is now a markup over the wage rather than over the reservation wage, the real wage is lower than under efficient bargaining (and depends only on monopoly power in the goods market):

$$
\frac{W_{i}}{P}=\frac{1}{1+\mu}
$$

By implication, profit per unit is larger than under efficient bargaining.

Turn to the long run equilibrium. In the long run, the zero net profit condition gives:

$$
\frac{\mu(m)}{1+\mu(m)}=c, \text { or equivalently: } \quad \bar{\sigma} g(m)=1 / c
$$

So, an economy where firms have the right to manage has a larger number of firms, and thus a higher elasticity of demand, and thus a lower markup.

We saw that, given the number of firms, unemployment was higher. But the number of firms is larger, leading to a lower markup, and thus lower unemployment. Replacing $\mu(m)$ in (4.3) by its value from above gives:

$$
f(u)=\frac{(1-c)^{2}}{1-c+\beta c}
$$

Comparing it to the expression for unemployment in the benchmark model, (2.8), it follows that, if $\beta$ is positive, the unemployment rate is actually lower in the long run than under efficient bargaining.

Finally, the zero profit condition implies that the real wage is the same 
as under efficient bargaining, namely: ${ }^{5}$

$$
W_{i} / P=1-c
$$

Now consider the effects of labor market deregulation, i.e. of a decrease in $\beta$. In the short run, wages do not change, and unemployment decreases. As the profit rate also does not change, the long run is just like the short run. Thus, under right to manage, there is no intertemporal trade-off from this dimension of labor market deregulation: Workers gain in both the short and the long run.

This extension makes clear the role of the assumption that wages are distributive in our benchmark model. We believe that this is indeed the case: Wages are not fully allocative, and in the short run, a large decrease in wages may translate in an increase in rents going to firms rather than in an increase in employment. ${ }^{6}$

\section{Concave utility}

Assuming concave rather than linear utility for workers yields an interesting difference in the short run effects of labor market deregulation, i.e. a decrease in $\beta$. In the short run, deregulation leads to both lower real wages and higher unemployment (whereas, before, unemployment remained

\footnotetext{
${ }^{5}$ Note the distinct second-best flavor of these results. A shift to privately inefficient bargaining leads to unchanged real wages, and lower unemployment in the long run.

${ }^{6}$ Allowing for capital in the production function, together with a low short run elasticity of substitution between capital and labor and costs of adjustment to capital, also delivers small employment effects in the short run. These factors are surely important as well. (They cannot however deliver the decrease in both wages and employment in response to a decrease in $\beta$ that obtains in our next extension.)
} 
unchanged). This is in sharp contrast to movements along a labor demand curve, and, we shall argue later, may be relevant to understanding what happened in Europe in the 1990s.

Let us derive this result formally. ${ }^{7}$ Suppose that the utility of workers is given by a power transformation of our previous linear utility function:

$$
\tilde{V}_{j}=\frac{1}{1-\gamma} V_{j}^{1-\gamma}
$$

where $V_{j}$ was defined earlier as a CES function of consumptions of individual products, and $\gamma<1$. (We keep the assumption that entrepreneurs are risk neutral. This is not essential but is convenient).

In partial equibrium, and under efficient bargaining, the real wage and the relative price of firm $i$ are now given by:

$$
\frac{W_{i}}{P}=f(u)\left(\frac{1+\beta \mu}{1+\beta \gamma \mu}\right)^{\frac{1}{1-\gamma}}
$$

and

$$
\frac{P_{i}}{P}=\frac{W_{i}}{P} \frac{1+\mu}{1+\beta \mu}
$$

For $\gamma=0$, the results are the same as before. For $\gamma>0$, the solution is characterized in Figure 3. The contract curve, the set of employment and real wages for different values of $\beta$, is no longer vertical, but is now upward sloping. For $\beta=0$, the equilibrium is the same as before: The wage is equal to the reservation wage, and employment is such that the marginal revenue product is equal to the reservation wage. As $\beta$ increases however, the contract curve slopes up, with infinite slope at point $A$, and decreasing slope thereafter.

Thus, in partial equilibrium, a decrease in $\beta$ implies a movement down

\footnotetext{
${ }^{7}$ Our derivation is a straightforward extension of McDonald and Solow [1983].
} 


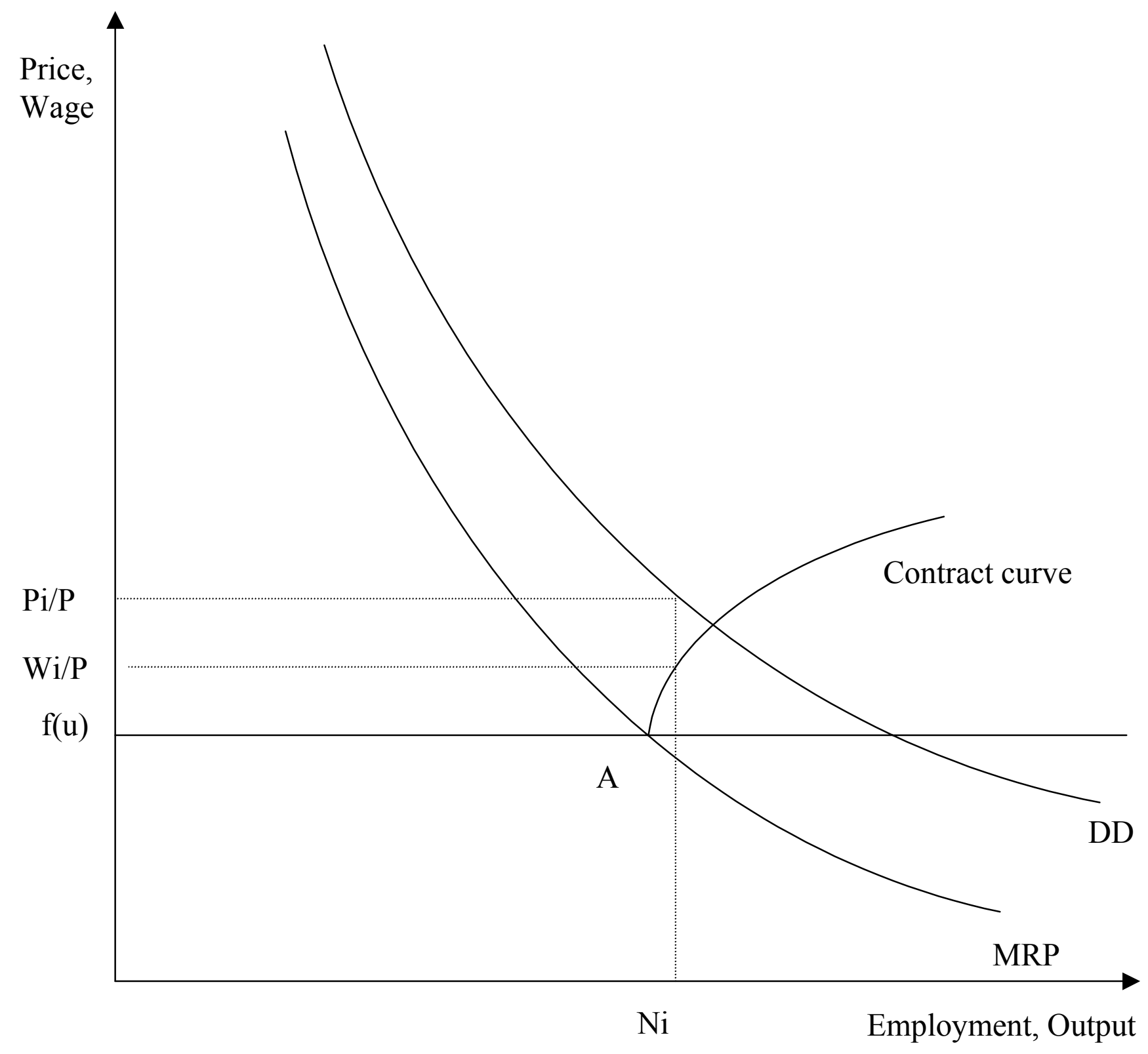

Figure 3. Partial equilibrium, with concave utility 
the contract curve, and thus a decrease both in employment and the real wage.

Turning to general equilibrium and setting $P_{i} / P=1$, the real wage and unemployment are given by:

$$
\begin{gathered}
\frac{W_{i}}{P}=\frac{1+\beta \mu}{1+\mu} \\
1=f(u)\left(\frac{1+\beta \mu}{1+\gamma \beta \mu}\right)^{\frac{1}{1-\gamma}} \frac{1+\mu}{1+\beta \mu}
\end{gathered}
$$

The real wage is given by the same expression as before. Unemployment can be shown to be a decreasing function of $\beta$. So, the partial equilibrium result extends to general equilibrium: In the short run, a decrease in the bargaining power of workers leads to both a decrease in their real wage and an increase in unemployment.

Turning to the long run general equilibrium, the condition that the profit rate be equal to $c$ gives:

$$
\bar{\sigma} g(m)=\frac{(1-\beta)}{c}
$$

So, just as in the benchmark model, a decrease in $\beta$ leads to an increase in the number of firms, and thus a decrease in the markup. As before, the real wage must be equal to $1-c$. There are now two opposite effects of labor market deregulation on unemployment. On the one hand, for a given number of firms, the lower value of $\beta$ leads to higher unemployment. On the other, the increase in the number of firms, and the lower markup, leads to lower unemployment. From the equations above, the net effect is however unambiguous: Unemployment decreases in the long run.

To summarize: At the center of discussions of labor market deregulation are often trade-offs between short-run and long-run effects. In our bench- 
mark model, the trade-off takes the form of lower wages in the short run, in exchange for lower unemployment in the long run. The first extension shows that to the extent that wages are allocative in the short run, the trade-off may be more attractive to workers: Under our specific assumptions, labor market deregulation has no effect on real wages, and decreases unemployment in both the short and the long run. The second extension shows however that, if workers have concave utility functions, the trade-off is even more stark than in the benchmark, with a decrease in real wages and an increase in unemployment in the short run, in exchange for lower unemployment in the long run.

\section{$5 \quad$ Interpreting movements in the labor share}

We now turn to the evidence. We first show how our approach leads to a different interpretation of the evolution of the labor share from that in the recent literature. We then look at, and interpret, the dramatic evolution of the labor share in continental Europe over the last 20 years.

\section{The labor share and the markup}

A large recent literature has focused on the evolution of the labor share, with the goal of inferring the evolution of the markup of the price over marginal cost, and by implication, learning about the pricing behavior of firms in imperfectly competitive markets. The logic of this approach is as follows:

- Assume a production function of the form $Y=F(N$, . ), where the dot stands for all factors other than labor.

- Assume that the measured wage is the correct measure of the cost of labor to the firm, so nominal marginal cost is given by $\mathrm{MC}=W / F_{N}$.

- Define the markup of price over marginal cost as $\mu$, so 


$$
P=(1+\mu) \mathrm{MC}=(1+\mu) W / F_{N}
$$

- The labor share, call it $\alpha$, is then equal to:

$$
\alpha \equiv \frac{W N}{P Y}=\frac{1}{1+\mu} \frac{F_{N}}{Y / N}
$$

The labor share is equal to one over one plus the markup, times the ratio of the marginal to the average product of labor.

Much of the work has gone into trying to construct accurate measures of the ratio of marginal to average product, so as to recover $\mu .^{8}$ Given that this aspect is not our focus here, let us assume, as we did in our benchmark model, that the production function is simply given by $Y=N$, so marginal and average product are both equal to one, and the labor share and the real wage are therefore equal. In this case, there is a very simple relation between the labor share and the markup:

$$
\alpha=\frac{W}{P}=\frac{1}{1+\mu}
$$

Variations in the share come entirely from variations in the markup, and thus from the pricing behavior of firms in the goods market.

This approach (obviously using a more general specification for the production function) has been used to construct time series for the markup, and characterize, for example, its cyclical behavior (Rotemberg and Woodford [1999] and references therein), its relation to inflation in an economy with nominal price setting (Gali and Gertler [1999], Sbordone [2000]), or the lower frequency evolution of markups in Europe over the past few decades (Bentolila and Saint-Paul [1999]).

\footnotetext{
${ }^{8}$ See the careful discussion in Rotemberg and Woodford [1999].
} 
From the perspective of our paper, the crucial assumption in that line of research is that the wage is an accurate measure of the cost of labor to firms. Under efficient bargaining, and more generally in any model in which the wage is not fully allocative, this assumption is not correct. Under efficient bargaining, the shadow cost of labor is the reservation wage, and the firm sets its price as a markup over this shadow cost. And this leads, as we have seen, to a different expression for the real wage - and, by implication, for the labor share. Instead of being given by equation (5.1), the share is given by:

$$
\alpha=\frac{W}{P}=\frac{1+\mu \beta}{1+\mu}
$$

The labor share now depends on imperfections in both the goods and the labor market. As in (5.1), it is a decreasing function of the markup, and thus of the monopoly power of firms. But it is also depends on the bargaining power of workers. The higher their power, the higher the labor share.

This has two practical implications. First, if the wage is not fully allocative, the construction of markups in the existing literature is incorrect. What is interpreted as an increase in the markup may in fact reflect lower bargaining power of workers in the labor market. Second, movements in the labor share may come from changes in the structure of either the goods or the labor market. In the rest of the section, we show how this approach can be used to interpret the evolution of the labor share in continental Europe over the last two decades.

\section{The evolution of unemployment and the labor share in Europe}

Figure 4 shows the two macroeconomic evolutions which motivated this research in the first place. It plots the unemployment rate, and the labor share in the business sector, for four major European countries, Germany, 


\section{Figure 4. Unemployment rates and labor shares}

Germany, France, Italy, and Spain, 1970-2000
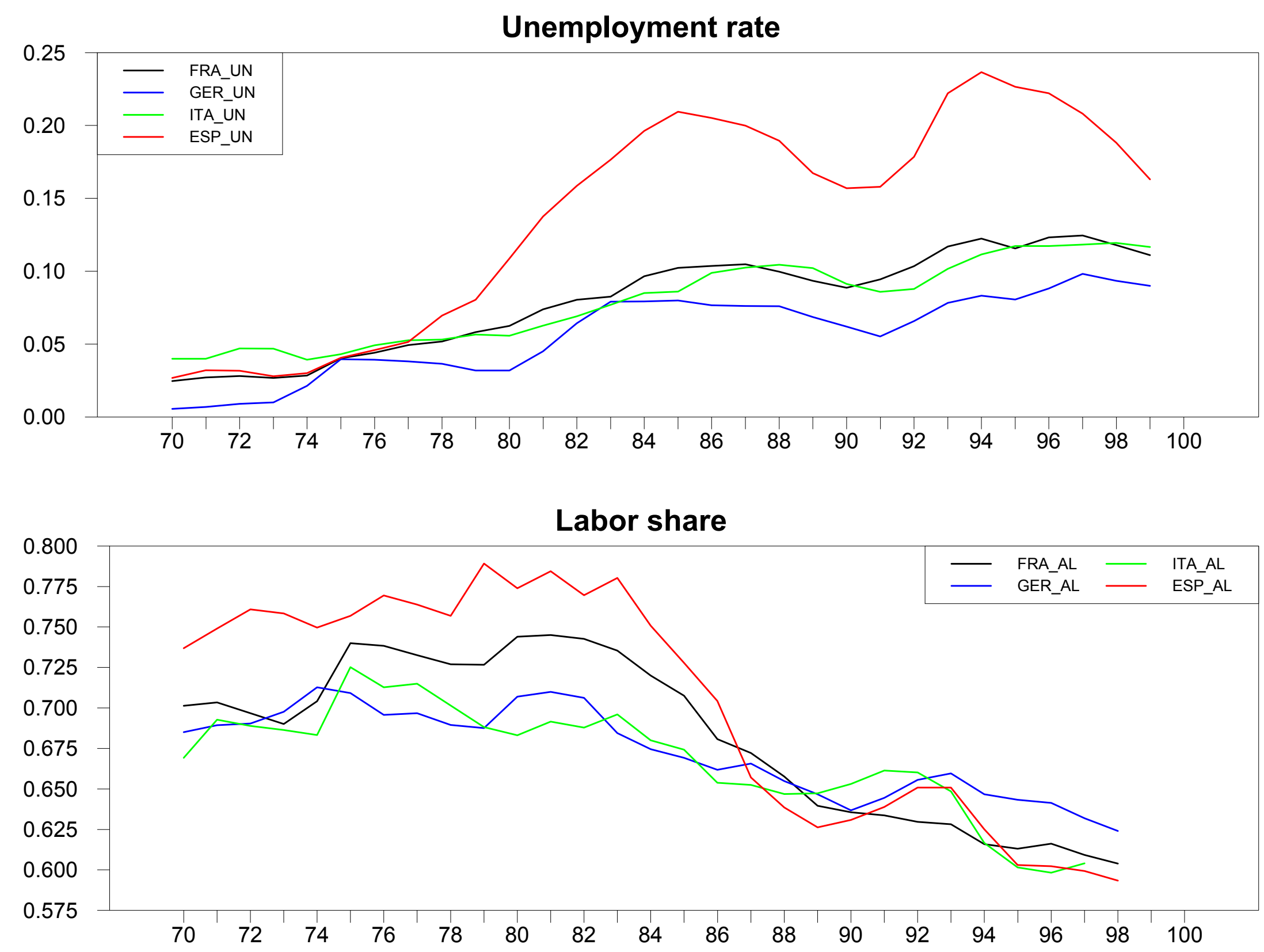
France, Italy, and Spain, since 1970. It points to two main facts:

- The increase in unemployment in the 1980s, and the persistence of high unemployment for much of the 1990s, in all four countries. Only in the last few years has unemployment started to decline, most dramatically in Spain, least so in Italy.

- The sharp decrease in labor shares, starting in the early to mid-1980s. For France, for example, the labor share, which had increased from $70 \%$ in the early 1970 s to $74 \%$ in the early 1980 s, has now decreased to $60 \%$, a decrease of $14 \%$ of GDP relative to the peak, $10 \%$ relative to the 1970 value. $^{9}$

The focus on only four countries is for visual convenience: The decrease in labor shares has been common to most continental European countries. This is in sharp contrast however to the United States, where the labor share has remained extremely stable.

One can think of a number of explanations for these two facts, many of them having nothing to do with rents, regulation, or deregulation. One is that an increase in the wage (relative to the level of technology), starting in the 1970s, led initially to an increase in the labor share and not much adverse effect on employment. But, as firms started substituting away from labor, the labor share started to fall, and unemployment to rise, the evolution reflected in Figure 4. In that interpretation, the low labor share and high unemployment in the 1990s reflect too high a wage, and a high elasticity of substitution between capital and labor in the long run.

The purpose of an earlier paper by one of the authors (Blanchard [1997]) was to examine this and other explanations. The conclusion was that ex-

\footnotetext{
${ }^{9}$ The business sector data stop in 1998. Based on aggregate rather than business sector evidence, there is no evidence of substantial change since then.
} 
planations based on the reaction of firms to wages and the cost of capital in competitive goods and labor markets just could not explain the data. Readers are refered to that article (and to the follow-up in Blanchard [2000]) for a full treatment. But the basic reason for that conclusion can be shown simply:

Assume that firms indeed act as profit maximizers in competitive goods and labor markets. Assume also that, leaving aside adjustment costs, their production function exhibits constant returns to capital and labor. Assume finally that technological progress is Harrod neutral - the assumption required to obtain a balanced growth path - so the production function can be written as $Y=F(A N, K)$, where $A$ is the technological level.

Under those two assumptions, and ignoring costs of adjustment, profit maximization implies the following relation between the labor-capital ratio and the real wage:

$$
(A N / K)=f(W / A), \quad f^{\prime}(.)<0
$$

Call $A N$ labor in efficiency units, and $W / A$ the wage in efficiency units. Then, this relation states, the ratio of labor in efficiency units to capital should be a decreasing function of the wage in efficiency units, with the property of $f($.$) deriving from the properties of the production function.$ This suggests a simple step, that of building and plotting $A N / K$ and $W / A$ for each country over the period. This is done in Figure 5, which gives the evolution of the logarithms of $A N / K$ and of $W / A$, from 1971 on (not all the data are available for 1970), for each country. Both series are normalized to zero in 1971. The figure yields two important conclusions:

- The 1970s were indeed associated with an increase in $W / A$, thus with a "wage push". Associated with this increase was a sharp drop in the labor-capital ratio, in $A N / K$.

- From the early 1980 s on however, $W / A$ started decreasing in all four 
Figure 5. $\log (a n / k)$ and $\log (w / a)$.

1970-1998. $1970=0$
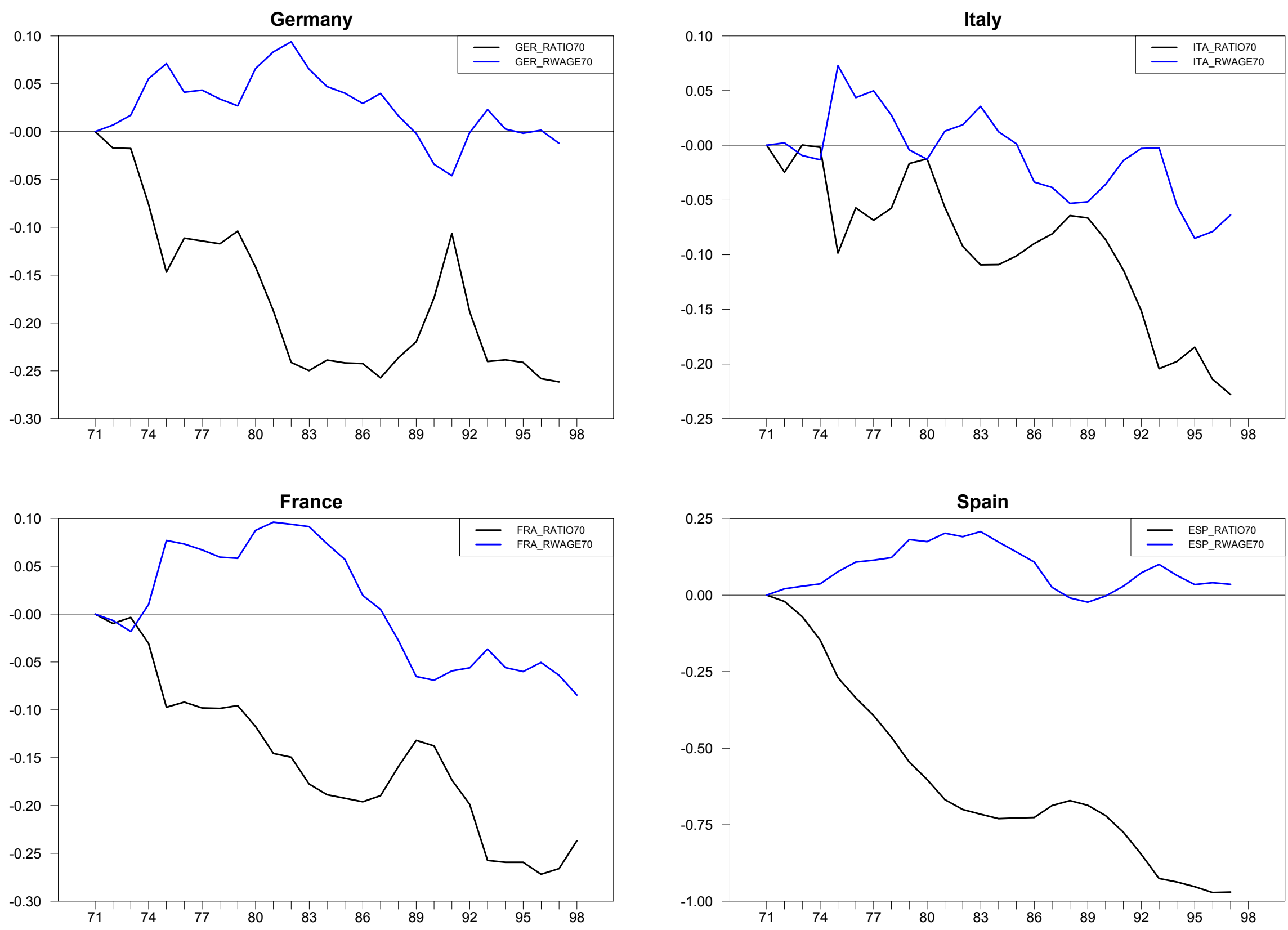
countries. By the late 1980s, it was actually lower than its 1971 value in all four countries. Yet, and here is the proximate cause for the decrease in the labor share, this return of $W / A$ to its earlier level has not been associated with a return of the labor-capital ratio to its earlier level. The ratio now appears to have stabilized, but at a level substantially lower than in the early 1970s. Thus, the decrease in the wage since the mid-1980s has not been associated with an increase in employment.

Could this evolution be explained by the long lags and the expectational effects coming from a putty-clay technology, or by costs of adjusting factor proportions more generally? This seems unlikely. Only expectations of large increases in $W / A$ in the future could explain why the labor-capital ratio has recovered so little, if at all. Given the emphasis on wage moderation in Europe today, this seems implausible, and suggests the need to look for other explanations.

\section{Labor market deregulation?}

The model developed in this paper suggests one such explanation, namely a decrease in the bargaining power of workers, a decrease in $\beta$, starting some time in the mid-1980s. ${ }^{10}$

As we saw, such a shift can initially generate both a decrease in the real wage and in the labor share, and either no improvement (if the contract curve is vertical) or an increase (if the contract curve is upward sloping) in unemployment. Both implications seem to fit the facts. Under this in-

\footnotetext{
${ }^{10}$ This is not the only alternative explanation. Another is that technological progress, rather than being Harrod neutral, has become biased against labor in the last 20 years in Europe (but not in the United States). For further discussion of this and other alternatives, see Blanchard [1997] and Blanchard [2000].
} 
terpretation, the decrease in the bargaining power of workers, starting in the mid 1980s, has led to a reduction in the real wage at a given level of employment, and, by implication, a reduction of the labor share. So far, the employment effects have been limited. But, our model suggests, the future should be brighter, and employment should eventually more than recover. Indeed, the steady decline in unemployment since 1998 may be a sign that these dynamics are now at work.

How plausible is this interpretation? Note that the argument must have two elements. The first is that, since the mid 1980s, Europe has gone through labor market deregulation, at least in the sense of a decrease in the bargaining power of workers. The second is that the effects of labor market deregulation have so far dominated the effects of product market deregulation. In terms of our model, to explain the decrease in the labor share, it must be that the decline in $\beta$ has dominated the decline in $\mu$. Otherwise, our model implies, we would have seen an increase, not a decrease, in the labor share, and a stronger decline in unemployment.

How much direct evidence is there for each of these two elements? The honest answer must be: Not much, either for, or against. The main reason for our ignorance comes from a number of conceptual and empirical issues, first in developing measures of the relevant institutions, second in constructing the evolution of these measures over time.

Most of what we know at this point comes from work by the OECD on changes in product market and labor market regulations in member countries. Initial results from the development and the construction of a number of measures are reported in Boeri et al. [2000]. Two of findings of the study are relevant here:

- First, the quantitative evidence points indeed to deregulation both in goods and labor markets in Europe since the mid 1980s.

- Second - and this goes against the hypothesis developed here - product 
market deregulation, which has taken place largely as a result of E.U. initiatives, has been widespread, if slow moving. By contrast, labor market reforms have been more piecemeal. This second piece of evidence may not be conclusive however. The indicators constructed by the OECD and examined by Boeri et al for the labor market focus on employment protection, unemployment benefits, and the generosity of pensions. Of those, only the first is likely to be related to $\beta$ in our model. And, going beyond these indicators, the larger picture appears to be one of a weakening of unions throughout Europe. The unionization rate has decreased, often substantially, in most European countries over the last 15 years (see for example Booth et al. [2000].) The general attitude of governments towards unions also appears to have changed, and so has the attitude of unions themselves.

Indeed this weakening of unions points to potential interactions between product market and labor market deregulation, the topic to which we now turn.

\section{Interactions between product and labor market deregula- tion}

Another dimension in which our analysis can be helpful is in thinking about the political economy of deregulation. The questions are many, ranging from simple to complex, from positive to normative. Consider the following list:

- Can we explain exactly why workers so strongly oppose labor market deregulation (in the sense of a decrease in $\beta$ )? Who loses and who gains? What are the intertemporal trade-offs?

- Can we explain why workers also so often oppose product market deregulation - although not always with the same intensity as they do labor market deregulation? 
- If we think of the degree of regulation as endogenous, say as the result of lobbying by workers or firms, how are deregulation in the labor market and the product market likely to interact? Is one likely to help or hinder the other?

- More pointedly, in light of the macroeconomic facts in the previous section, could it be the case that the product market deregulation coming from European integration has naturally led to labor market deregulation? Might the reaction be strong enough so as to lead to the observed decrease in the labor share?

Fully answering these questions would require another paper. But our model gives a number of hints, which we believe are likely to be robust to further analysis.

We proceed in two steps. The first, pedestrian, step is simply to characterize utility, for both employed and unemployed workers, together with the unconditional probability of being unemployed (equivalently the unemployment rate), in the short and the long run. The second is then to return to the questions above, and point to some of the implications of our results.

\section{Utilities, the Unemployment Rate, and Firm Employment}

Denote the (one period) utility of an employed worker by $V^{N}$, and the (one period) utility of an unemployed worker by $V^{U}$. Then, collecting earlier results:

In partial equilibrium, and in the short run, the utility of being employed is given by:

$$
V^{N}=(1+\beta \mu) f(u)
$$

Employment in firm $i$ is given by:

$$
N_{i}=N(1+\mu)^{-\sigma}
$$


In general equilibrium, and still in the short run, the two utilities are given by:

$$
V^{N}=\frac{1+\beta \mu}{1+\mu} \quad V^{U}=\frac{1}{1+\mu}
$$

The unemployment rate, and employment in firm $i$ are given by:

$$
u \mid f(u)=\frac{1}{1+\mu} \quad N_{i}=\frac{L}{m}(1-u)
$$

In general equilibrium, and in the long run, the two utilities are given by:

$$
V^{N}=1-c \quad V^{U}=1-\frac{c}{1-\beta}
$$

The unemployment rate, and employment in firm $i$ are given by:

$$
u \mid f(u)=1-\frac{c}{1-\beta} \quad N_{i}=\frac{L}{m}(1-u) \text { where } m \mid \bar{\sigma} g(m)=\frac{1}{c}
$$

To go from this to a characterization of the effects of deregulation on welfare, we need three more elements:

- First, and obviously, the discount rate used by workers and entrepreneurs to assess utility in the second period - the long run.

- Second, a characterization of when the reform is introduced-for example before or after workers know whether they are employed or unemployed in the first period - the short run. ${ }^{11}$

\footnotetext{
${ }^{11}$ These veil-of-ignorance issues are familiar from the research on political economy of reform. For example, see Fernandez and Rodrik [1991].
} 
- Third, a characterization of the rules mapping aggregate and firm employment into individual employment probabilities. ${ }^{12}$ If, for example, employment status in the long run is unrelated to employment status in the short run, then all workers need to know is what happens to the unemployment rate in the long run. If, instead, workers currently employed by a firm have priority in that firm's employment in the long run, then they will also care about what happens to employment in the firm: If, for example, reform leads to entry of new firms, employment in existing firms may decline, even if aggregate employment increases.

We have nothing to add here, nor do we want to give an encyclopedic treatment of all possible cases. In what follows, we focus on the case where reforms are announced after the pre-reform equilibrium has been realizedso workers know their pre-reform employment status. We shall assume that those workers who are currently employed have priority in employment at the same firm in the long run - so, if there is no decrease in the employment level of an incumbent firm, their probability of unemployment is zero. Finally, we shall concentrate on the welfare of those workers employed pre-reform.

\section{Labor Market Deregulation}

The first two effects of labor deregulation (a decrease in $\beta$ ) are to decrease wages in the short run, leave them unchanged in the long run. For a worker who is sure to be employed in both periods, the effect is thus unambiguously negative.

There are employment effects however. In the short run, both aggregate unemployment and firm employment remain unchanged. But, in the long run, entry of firms is likely to decrease employment in incumbent firms

\footnotetext{
${ }^{12}$ The issues are familiar from insider-outsider models. They play a central role for example in the analysis of labor market reform by Saint-Paul [2000].
} 
(Recall that the effect is formally ambiguous, because of the decrease in aggregate unemployment.) This in turn implies that the currently employed workers now face a positive probability of becoming unemployed, further decreasing their utility.

In short, why currently employed workers oppose labor market deregulation is rather straightforward: They lose from it. Those who gain are those who would have been unemployed in the future: some of them end up employed, and those who remain unemployed have a higher level of utility.

\section{Product market deregulation}

Think of a deregulation as a decrease in $\mu$. As we have seen, in the short run, this decrease can be achieved through an increase in $\bar{\sigma}$; in the long run, it must be achieved through a decrease in $c$.

In both the short and the long run, the effects on the utility of workers, whether employed or unemployed, are unambiguously favorable: A decrease in $\mu$ leads to an increase in both $V^{N}$ and $V^{U}$ in the short run; a decrease in $c$ also leads to an increase in $V^{N}$ and $V^{U}$ in the long run.

So why don't workers more strongly endorse product market deregulation? The model suggests two reasons.

First, in partial equilibrium, deregulation decreases the rents to the firm, and thus the rents to the workers. Under symmetry, this partial equilibrium perception is, as we have seen, misleading, as the decline in prices elsewhere more than compensates workers for the decrease in rents. But, if deregulation only affects part of the economy (because the rest of the economy was competitive, or because it remains regulated), then the partial equilibrium argument may extend to general equilibrium. If the deregulated sector is small enough, the partial equilibrium effect will indeed dominate, and make workers in that sector worse off.

Second, and as in the case of labor market deregulation, lower markups come, in the long run, from entry of new firms, and higher competition. 
Thus, employment in incumbent firms is likely to decrease, increasing the risk of unemployment for currently employed workers. This again may lead them to oppose product market deregulation, despite higher wages and lower unemployment.

\section{Interactions}

The remarks above suggest that product market deregulation, which increases the wage, may help implement labor market deregulation, which initially decreases it. Because both however lead to entry, and a likely decrease in employment in incumbent firms, this may not be enough to get the support of employed workers.

We want to explore a different interaction however, based on the notion that, if product market deregulation decreases total rents, the incentives for workers to appropriate a proportion of these rents may be decreased, leading to labor market deregulation. ${ }^{13}$

To do so, we proceed as follows. We think of product market deregulation as a decrease in $\bar{\sigma}$, which in turn leads to a decrease in $\mu$. We think of employed workers as lobbying for a higher value of $\beta$. We assume that they maximize the utility of being employed, net of lobbying costs:

$$
\frac{1+\beta \mu}{1+\mu}-\frac{a}{2} \beta^{2}
$$

The first term is the short run utility when employed. The second is the cost of lobbying, which is taken to be quadratic in $\beta$, and $a$ is a parameter.

Maximization with respect to $\beta$ yields:

\footnotetext{
${ }^{13}$ This idea has been explored, in a partial equilibrium context, in both the labor and industrial organization literature. See for example Joskow and Rose [1989], Section 9, for a survey, or more recently Neven et al. [1998], and articles in the Summer 1999 issue of the Journal of Economic Perspectives.
} 


$$
\beta=\frac{1}{a} \frac{\mu}{1+\mu}
$$

So a decrease in $\mu$ leads to a decrease in $\beta$. Product market deregulation leads to labor market deregulation. Having less rents to appropriate, unions fight less hard, or nearly equivalently, workers are less likely to join unions, making them weaker.

Can product market deregulation in the end lead to a lower, not a higher, real wage? In other words, can the indirect effect, through the decrease in $\beta$, dominate the direct effect through the decrease in $\mu$ (by the envelope theorem, we know that net utility above must go up if $\mu$ goes down)?

The answer is yes. It is straightforward to show that a condition for product market deregulation to lead to a lower real wage is that $(2 / a) \mu /(1+$ $\mu$ ) $>1$ (or equivalently that $\beta>1 / 2$ ). This will occur if $a$ is small enough, so $\beta$ responds strongly to $\mu$.

Our formalization is little more than an example. Further steps would be to endogenize $\mu$, and to consider both the short and the long run. But it has two merits. First, it shows some of the complementarities between the two types of deregulation. Second, it may help explain the macroeconomic facts we saw in the previous section, the decline in the labor share and the persistence of unemployment in Europe since the mid 1980s. ${ }^{14}$

\footnotetext{
${ }^{14} \mathrm{~A}$ rather different way in which higher product market competition may have affected labor market outcomes is by putting into question "efficient bargaining" in the labor market. As is well known, efficient bargaining is not time consistent: Given that the wage typically exceeds the marginal revenue product of labor, firms would like, ex-post, to reduce employment below the level agreed to in the bargain. (In Figure 1, given $W_{i} / P$, the firm would increase profit in the short run by choosing a level of employment on the MRP curve, thus to the left of $N_{i}$ ).
} 


\section{Conclusions}

Our main purpose in this paper was to construct a general equilibrium model with rents and bargaining, and use it to think about the effects of product and labor market deregulation. Our formalization strategy was to construct what we think is the simplest model required for those purposes. Further progress clearly requires extending the model, in at least two dimensions:

- First, by fleshing out the relation of the parameters of the model to the the specific institutions which determine rents in the labor and goods market. A natural way of doing so is by integrating our approach with that of Caballero and Hammour (for example Caballero and Hammour [1998], Caballero and Hammour [1999]).

- Second, by allowing for a richer description of technology, in particular by allowing for both labor and capital in production, along the lines of Spector [2000]. Introducing capital would not only lead to a richer picture, but also allow to capture the fight for rents between workers, entrepreneurs, and rentiers, and, by implication, the interactions

If firms have long enough horizons, they may still decide to choose the efficient outcome; by foregoing profits in the short run, they are able to achieve a more efficient and more profitable outcome in the long run (see Espinosa and Rhee [1989]). Higher product market competition, however, may make it more tempting to achieve short-run profits. Under this interpretation, what we have seen is a change in the nature of bargaining, leading firms to reduce employment at a given real wage. If so, the qualitative effects are very similar, both in the short and the long run, to those of a decrease in $\beta$. Using our earlier results for the characterization of the economy under efficient bargaining and ex-post determination of employment, it follows that this change in bargaining leads to a decrease in the labor share and an increase in unemployment in the short run, and to lower unemployment in the long run. 
between labor, product, and financial market reform.

Building on these two extensions, one should then revisit the issues we discussed in the previous two sections.

In Section 5, we argued that the evolution of the labor share and unemployment in Europe in the last 20 years was suggestive of a movement towards labor market deregulation. But here, much work remains to be done to identify the respective roles of biased technological progress, of the adjustment of factor proportions to factor prices, and of changes in the distribution and size of rents due to changes in regulation.

In Section 6, we focused on the political economy interactions between product and labor market deregulation. But, here again, we only scratched the surface. Progress here also requires focusing on the role of specific institutions, as well as building on and integrating the work already done on the political economy of labor market and of product market reform. 


\section{References}

Bentolila, S. and Saint-Paul, G., 1999, Explaining movements in the labor share, Working Paper 9905, CEMFI, Madrid.

Blanchard, O., 1997, The medium run, Brookings Papers on Economic Activity 2, 89-158.

Blanchard, O., 2000, The Economics of Unemployment. Shocks, Institutions, and Interactions, Lionel Robbins Lectures, MIT Press, forthcoming.

Boeri, T., Nicoletti, G., and Scarpetta, S., 2000, Regulation and labour market performance, Discussion Paper 2420, CEPR.

Booth, A., Burda, M., Calmfors, L., Checchi, D., Naylor, R., and Visser, J., 2000, What do unions do in Europe?, mimeo, Fondazione Rodolfo DeBenedetti.

Caballero, R. and Hammour, M., 1998, The macroeconomics of specificity, Journal of Political Economy 106(4), 724-767.

Caballero, R. and Hammour, M., 1999, Jobless growth: appropriability, factor substitution and unemployment, Carnegie-Rochester Conference Series on Public Policy.

Espinosa, M. and Rhee, C., 1989, Efficient wage bargaining as a repeated game, Quarterly Journal of Economics 104-3, 565-588.

Fernandez, R. and Rodrik, D., 1991, Resistance to reform: Status quo bias in the presence of individual specific uncertainty, American Economic Review 81, 1146-1155.

Gali, J. and Gertler, M., 1999, Inflation dynamics: A structural econometric analysis, Journal of Monetary Economics 44, 195-222.

Joskow, P. and Rose, N., 1989, The effects of economic regulation, Handbook of Industrial Organization II, 1450-1506, R. Schmalensee and R.D. Willig, eds. Amsterdam: Elsevier Science Publishers.

Layard, R. and Nickell, S., 1990, Is unemployment lower if unions bargain over 
employment?, Quarterly Journal of Economics 105-3, 773-787.

McDonald, I. and Solow, R., 1983, Wage bargaining and employment, American Economic Review 73, 896-908.

McKinsey Global Institute, 1997, France and Germany.

Neven, D., Roller, L.-H., and Zhang, Z., 1998, Union power and product market competition: Evidence from the airline industry, CEPR Discussion Paper (1912).

Rotemberg, J. and Woodford, M., 1999, The cyclical behavior of prices and costs, Handbook of Macroeconomics 1B, 1051-1133, J. Taylor and J. Rotemberg eds, Elsevier.

Saint-Paul, G., 2000, The Political Economy of Labor Market Reforms, Oxford University Press, Oxford, forthcoming.

Sbordone, A., 2000, An optimizing model of U.S. wage and price dynamics, mimeo, Rutgers University.

Spector, D., 2000, Competition and the capital-labor conflict, mimeo, MIT. 